\title{
Manipulation of Precursor Reactivity for Facile Synthesis of Heterostructured and Hollow Metal Selenide Nanocrystals
}

\author{
Jessica Q. Geisenhoff, Ashley K. Tamura and Alina M. Schimpf* \\ Department of Chemistry and Biochemistry, University of California, San Diego, La Jolla, CA \\ 92093, USA \\ *Electronic address: aschimpf@ucsd.edu
}

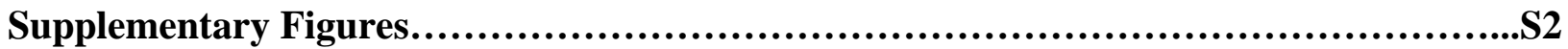

Figure S1. Line-scan of STEM-EDS mapping images of $\mathrm{Ni}_{3} \mathrm{Se}_{4} / \mathrm{WSe}_{2}$ heterostructures......S2

Figure S2. Additional STEM-EDS mapping images of $\mathrm{Ni}_{3} \mathrm{Se}_{4} / \mathrm{WSe}_{2}$ heterostructures ........S2

Figure S3. High-resolution TEM images of $\mathrm{Ni}_{3} \mathrm{Se}_{4} / \mathrm{WSe}_{2}$ heterostructures .................S3

Figure S4. TEM image showing gradual WSe 2 shell-growth on $\mathrm{Ni}_{3} \mathrm{Se}_{4}$ nanocrystals.........S3

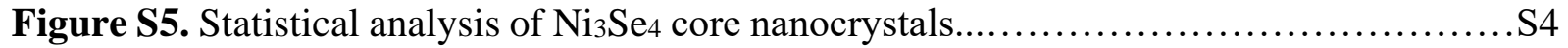

Figure S6. STEM-EDS mapping images of small particles............................S4

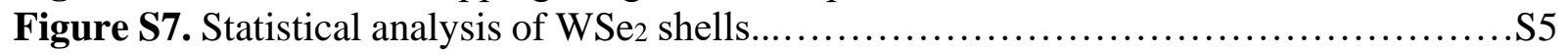

Figure S8. $\mathrm{Ni}_{3} \mathrm{Se}_{4} / \mathrm{WSe}_{2}$ heterostructures synthesized in the presence of $100 \mathrm{eq} \mathrm{OA} / \mathrm{W} \ldots . . . \mathrm{S} 5$

Figure S9. TEM images of $\mathrm{WSe}_{2}$ shell-growth on $\mathrm{Ni}_{3} \mathrm{Se}_{4}$ in the absence of OA..............S6

Figure S10. Line-scan od STEM-EDS mapping images showing preferred edge-growth......S6

Figure S11. TEM of 5-min aliquot for shell-growth in the presence of 100 eq OA..........S7

Figure S12. $\mathrm{Ni}_{3} \mathrm{Se}_{4} / \mathrm{WSe}_{2}$ heterostructures synthesized in the presence of 100 eq PAA/W....S7

Figure S13. STEM-EDS mapping images of hollow WSe2 nanocrystals .................S8

Figure S14. IR absorption showing $\mathrm{Et}_{2} \mathrm{~N}_{2} \mathrm{H}_{4}$ intercalation into hollow WSe 2 nanocrystals ... S9

Figure S15. Powder X-ray diffraction patterns showing $\mathrm{Et}_{2} \mathrm{~N}_{2} \mathrm{H}_{4}$ intercalation into WSe $\mathrm{Se}_{2} \ldots . . \mathrm{S} 9$

Figure S16. Electronic absorption spectrum of $\left[\mathrm{Ni}\left(\mathrm{Et}_{2} \mathrm{~N}_{2} \mathrm{H}_{4}\right)_{3}\right]^{2+} \ldots \ldots \ldots \ldots \ldots \ldots \ldots \ldots \ldots . . . . \ldots$

Figure S17. $\mathrm{Co}_{3} \mathrm{Se}_{4}$ synthesis with analogous conditions to Ni heterostructures.............S10

Figure S18. STEM-EDS mapping images of $\mathrm{Co}_{3} \mathrm{Se}_{4} / \mathrm{WSe}_{2}$ heterostructures ...............S11

Figure S19. STEM-EDS mapping images of $\mathrm{Cu}_{2-}{ }_{2} \mathrm{Se} / \mathrm{Cu}_{2} \mathrm{WSe}_{4}$ heterostructures ...........S 12

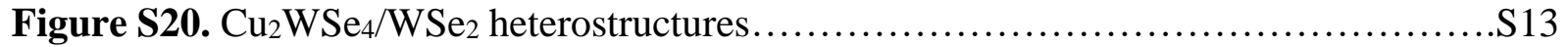

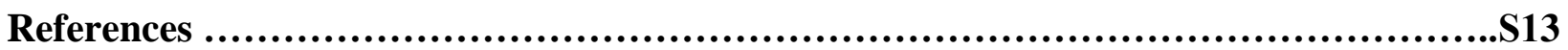




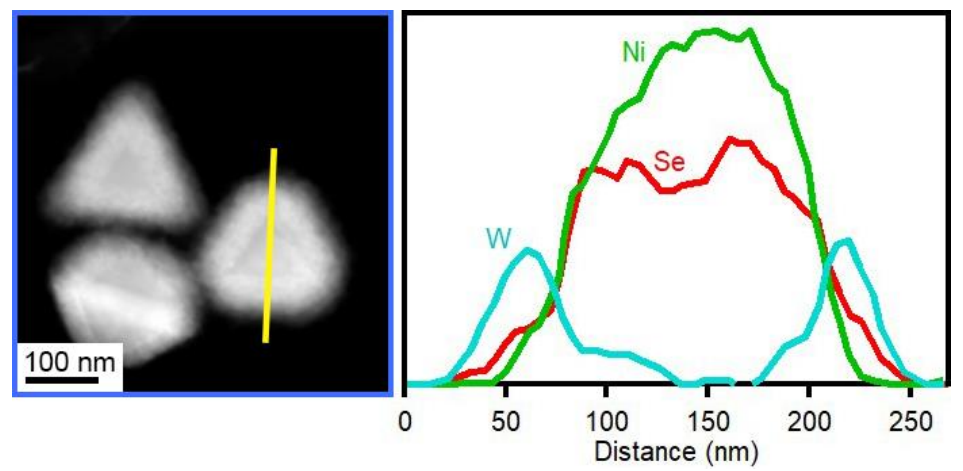

Figure S1. Line-scan corresponding to STEM-EDS mapping images shown in Figure 1.

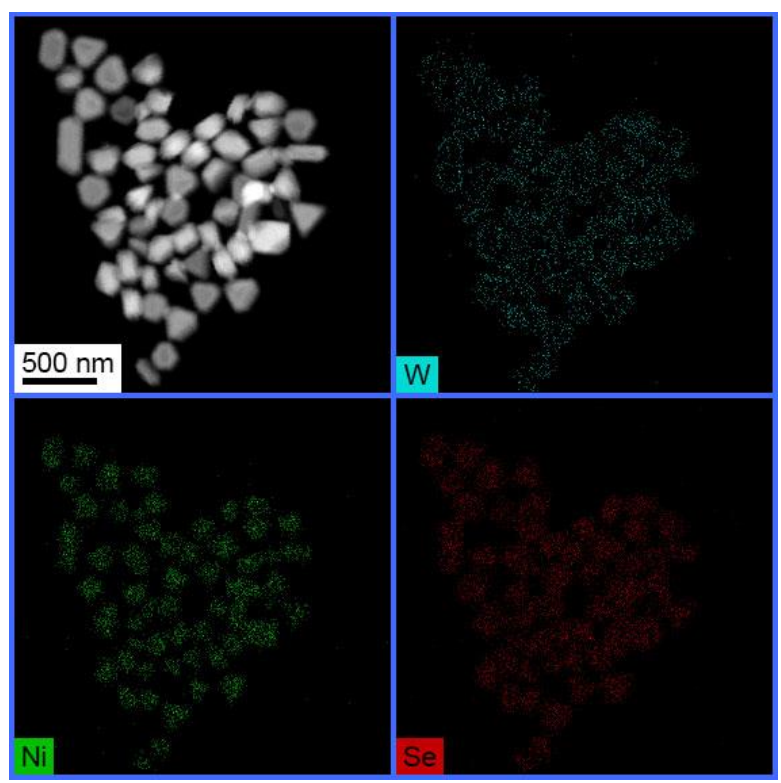

Figure S2. STEM-EDS mapping images of $\mathrm{Ni}_{3} \mathrm{Se}_{4} / \mathrm{WSe}_{2}$ heterostructures shown in Figure 1. 

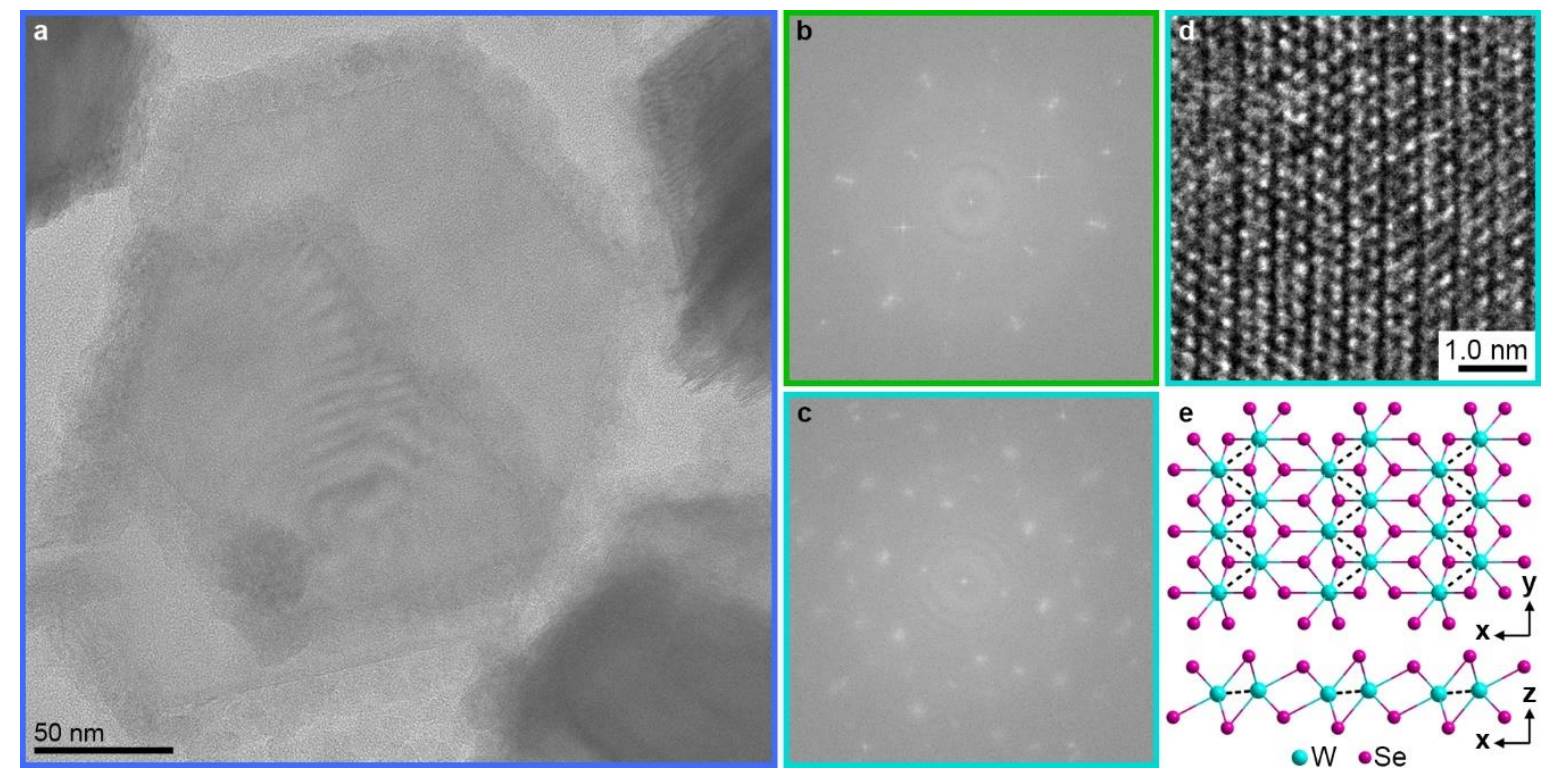

Figure S3. (a) TEM image of $\mathrm{Ni}_{3} \mathrm{Se}_{4} / \mathrm{WSe}_{2}$ heterostructures grown by rapid injection of $0.3 \mathrm{mmol} \mathrm{Ph}_{2} \mathrm{Se}_{2}$ in $1 \mathrm{ml} \mathrm{OA}$ into a solution of $\left.0.1 \mathrm{mmol} \mathrm{Ni(acac}\right)_{2}$ and $0.06 \mathrm{mmol} \mathrm{W(CO})_{6}$ in $17 \mathrm{ml} \mathrm{OA}$ and $2 \mathrm{~g}$ TOPO at $330{ }^{\circ} \mathrm{C}$. Corresponding FFTs on selected regions of the (b) $\mathrm{Ni}_{3} \mathrm{Se}_{4}$ core and (c) WSe 2 shell. (d) High-resolution TEM of the WSe2 shell displaying the zig-zag pattern characteristic of the $1 \mathrm{~T}^{\prime}(2 \mathrm{M})$ crystal phase. (e) Top and side views of a $1 \mathrm{~T}^{\prime}$ layer of $\mathrm{WSe}_{2}$ with the zig-zag pattern indicated in black dashed lines.

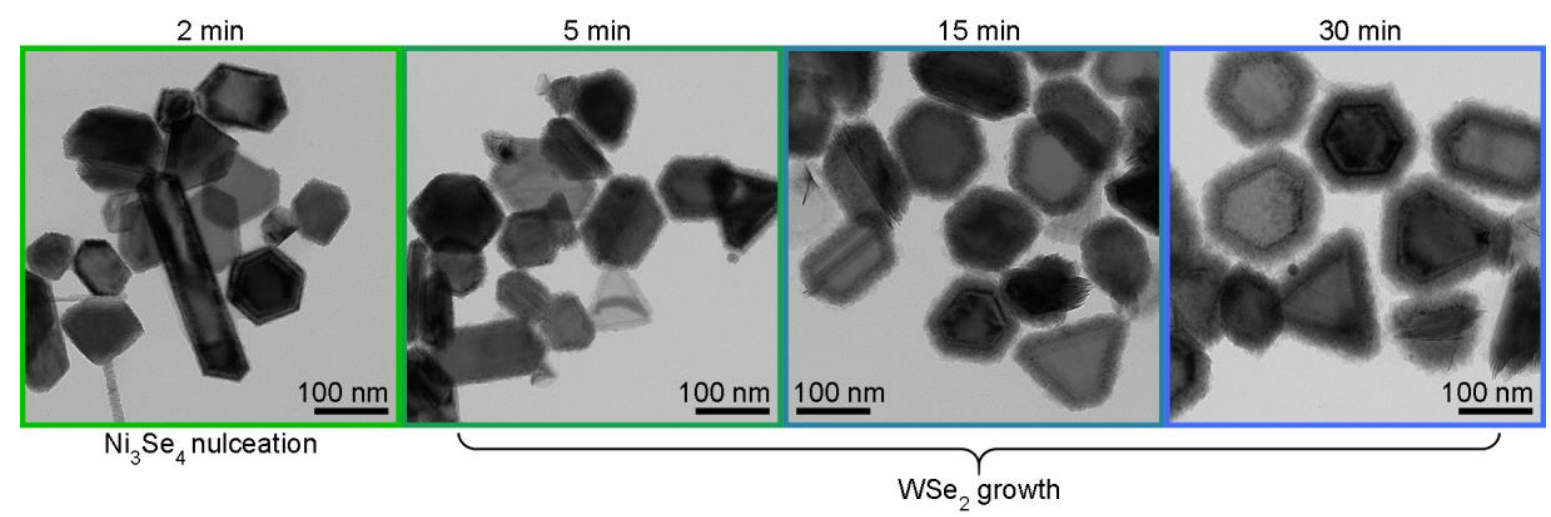

Figure S4. One-pot synthesis of $\mathrm{Ni}_{3} \mathrm{Se}_{4} / \mathrm{WSe}_{2}$ heterostructures grown by rapid injection of $0.3 \mathrm{mmol} \mathrm{Ph}_{2} \mathrm{Se}_{2}$ in $1.5 \mathrm{ml} \mathrm{OA}$ into a solution of $\left.0.1 \mathrm{mmol} \mathrm{Ni(acac}\right)_{2}$ and $0.06 \mathrm{mmol} \mathrm{W(CO)})_{6}$ in $17 \mathrm{ml} \mathrm{OA}$ and $2 \mathrm{~g}$ TOPO at $330^{\circ} \mathrm{C}$. (a) TEM images of aliquots taken 2, 5, 15 and 30 min after injection of $\mathrm{Ph}_{2} \mathrm{Se}_{2}$, showing that $\mathrm{WSe}_{2}$ shell thickness increases with time after injection. 


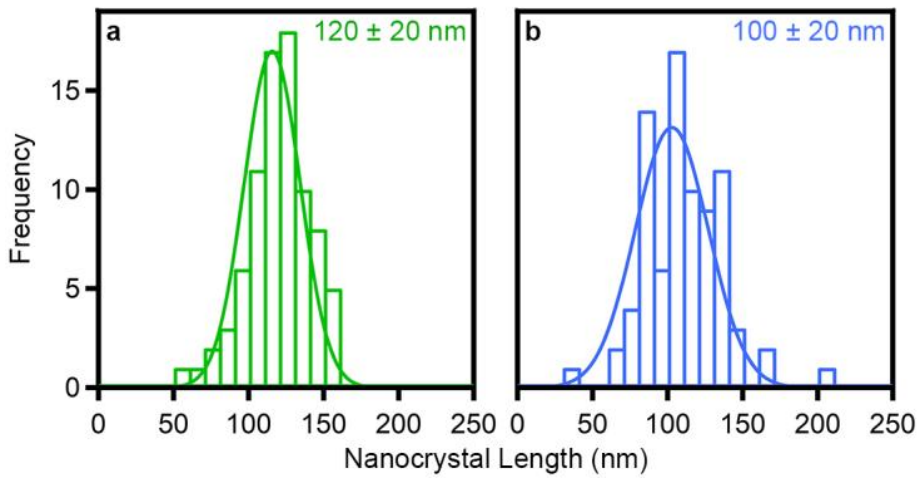

Figure S5. Statistical analysis of $\mathrm{Ni}_{3} \mathrm{Se}_{4}$ nanocrystal cores shown in Figure 1. Aliquots taken (a) 5 and (b) 30 min after injection of $\mathrm{Ph}_{2} \mathrm{Se}_{2}$.
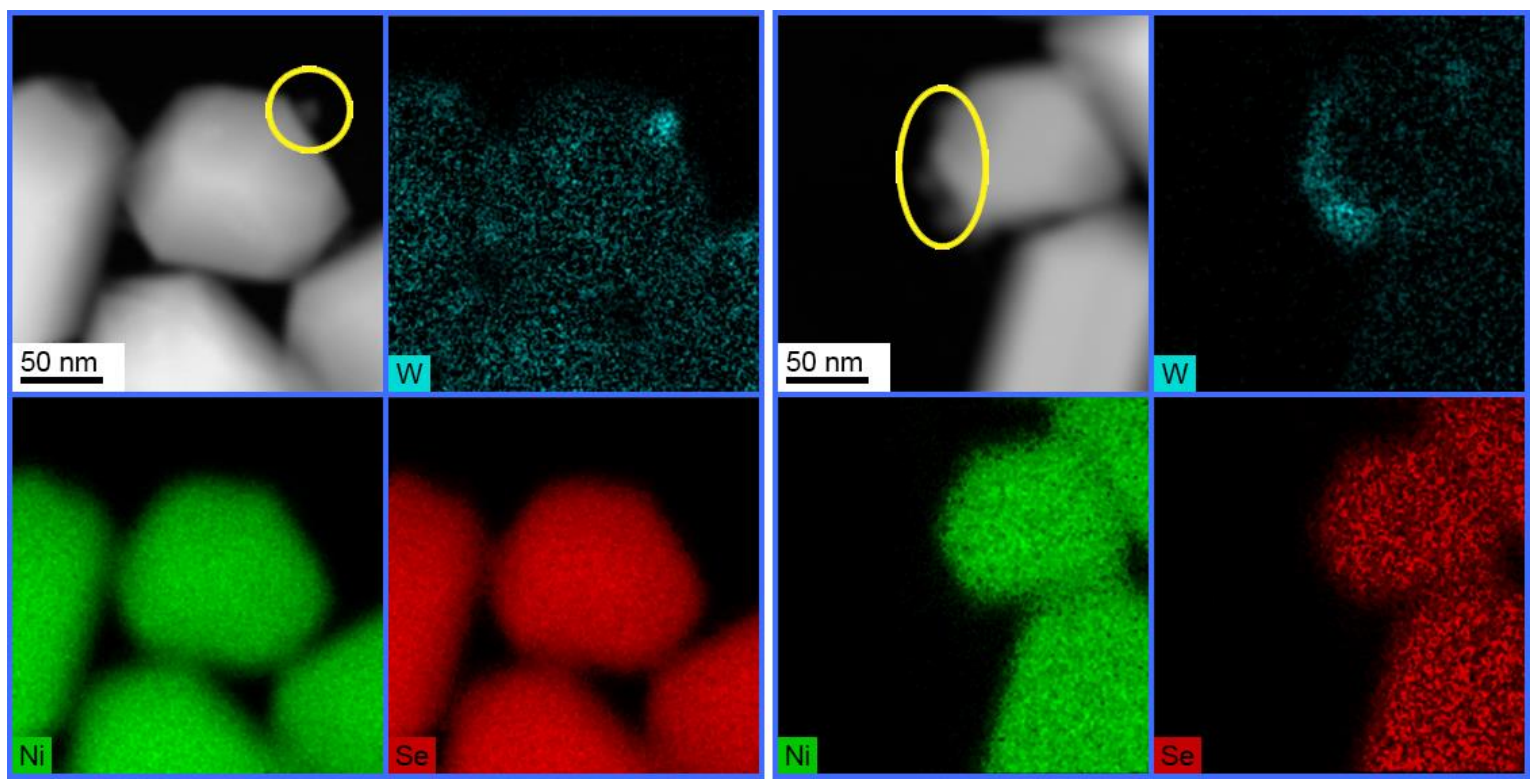

Figure S6. STEM-EDS mapping images of $\mathrm{Ni}_{3} \mathrm{Se}_{4}$ nanocrystals from an aliquot taken 2 min following rapid injection of $0.3 \mathrm{mmol} \mathrm{Ph}_{2} \mathrm{Se}_{2}$ in $1.5 \mathrm{ml} \mathrm{OA}$ into a solution of $0.1 \mathrm{mmol} \mathrm{Ni(acac})_{2}$ and $0.06 \mathrm{mmol} \mathrm{W}(\mathrm{CO})_{6}$ in $17 \mathrm{ml} \mathrm{OA}$ and $2 \mathrm{~g}$ TOPO at $330{ }^{\circ} \mathrm{C}$. 


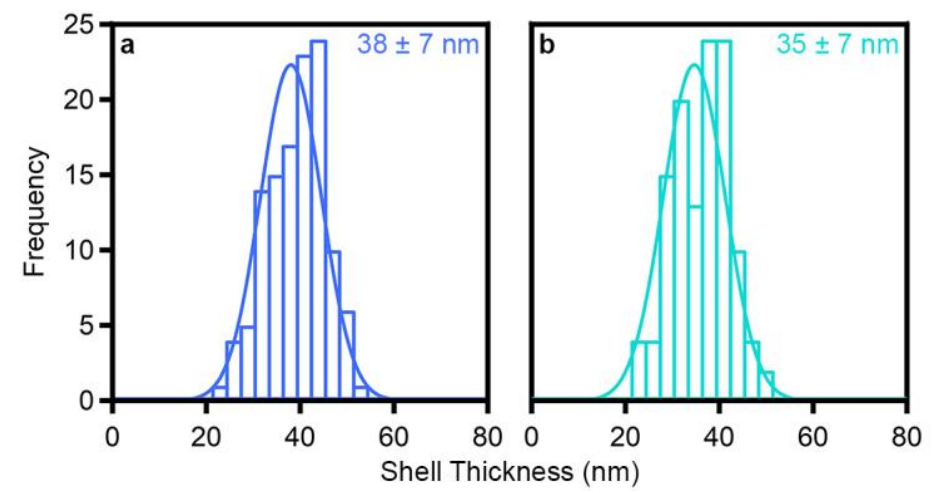

Figure S7. Statistical analysis of WSe2 shells shown in Figure S4 (a) before and (b) after removal of $\mathrm{Ni}_{3} \mathrm{Se}_{4}$ cores.
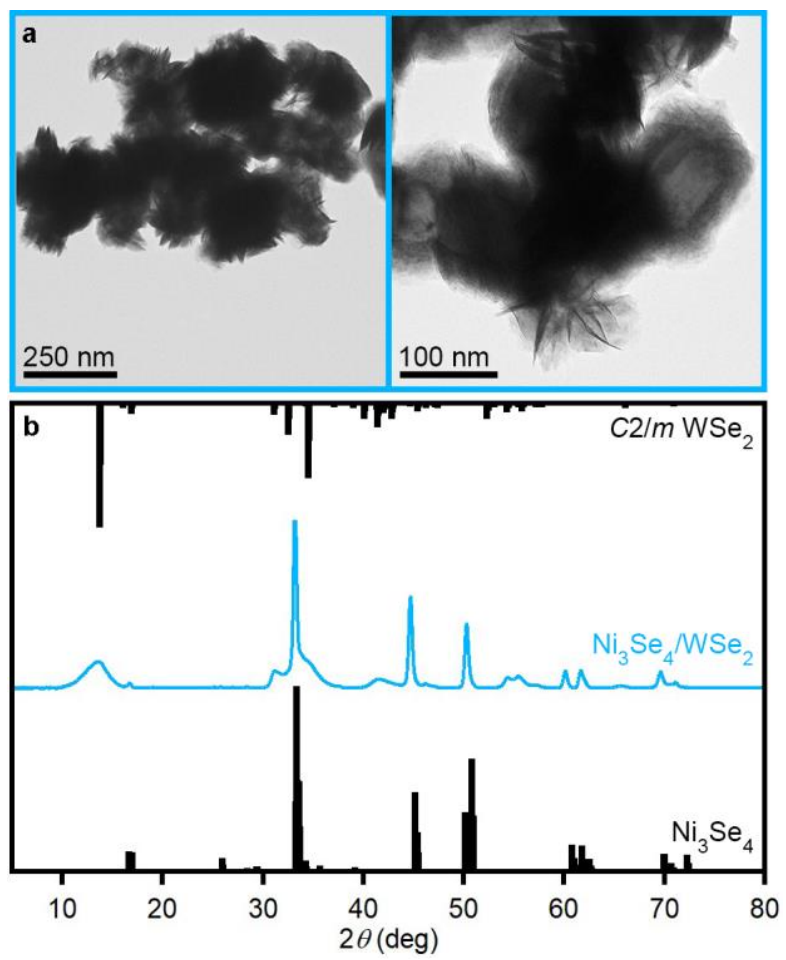

Figure S8. (a) TEM images and (b) powder X-ray diffraction pattern of $\mathrm{Ni}_{3} \mathrm{Se}_{4} / \mathrm{WSe}_{2}$ heterostructures synthesized in the presence of $100 \mathrm{eq} \mathrm{OA} / \mathrm{W}$. Specifically $0.15 \mathrm{mmol} \mathrm{Ph}_{2} \mathrm{Se}_{2}$ in $0.75 \mathrm{ml} \mathrm{ODE}$ was rapidly injected into a solution of $0.05 \mathrm{mmol} \mathrm{Ni(acac})_{2}$ and $0.03 \mathrm{mmol} \mathrm{W}(\mathrm{CO})_{6}$ in $0.9 \mathrm{ml} \mathrm{OA}$ and $8.9 \mathrm{~g}$ TOPO at $330{ }^{\circ} \mathrm{C}$. 


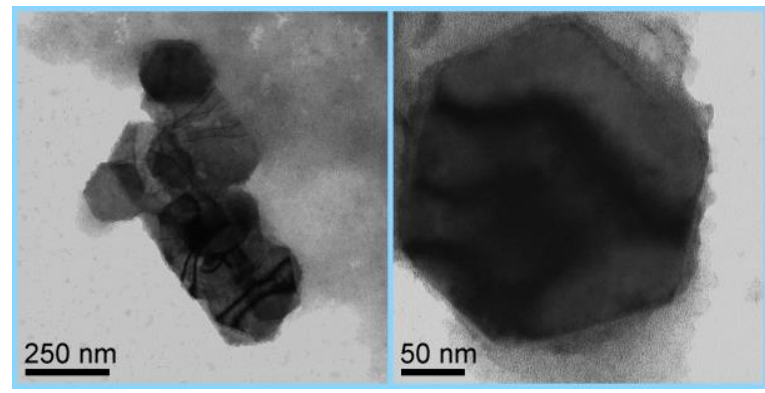

Figure S9. TEM images of attempt to grow $\mathrm{WSe}_{2}$ on $\mathrm{Ni}_{3} \mathrm{Se}_{4}$ without inclusion of OA. Specifically, $0.06 \mathrm{mmol} \mathrm{Ph}_{2} \mathrm{Se}_{2}$ was added to $1 \mathrm{ml} \mathrm{Ni} 3 \mathrm{Se}_{4}$ nanocrystal (Figure 3a) stock solution in ODE. This solution was injected into $0.03 \mathrm{mmol} \mathrm{W(CO})_{6}$ in $10 \mathrm{~g}$ TOPO at $330{ }^{\circ} \mathrm{C}$. The lack of OA or other coordinating ligand enables rapid, primary nucleation of small nanocrystals instead of only secondary nucleation onto the $\mathrm{Ni}_{3} \mathrm{Se}_{4}$ nanocrystals.
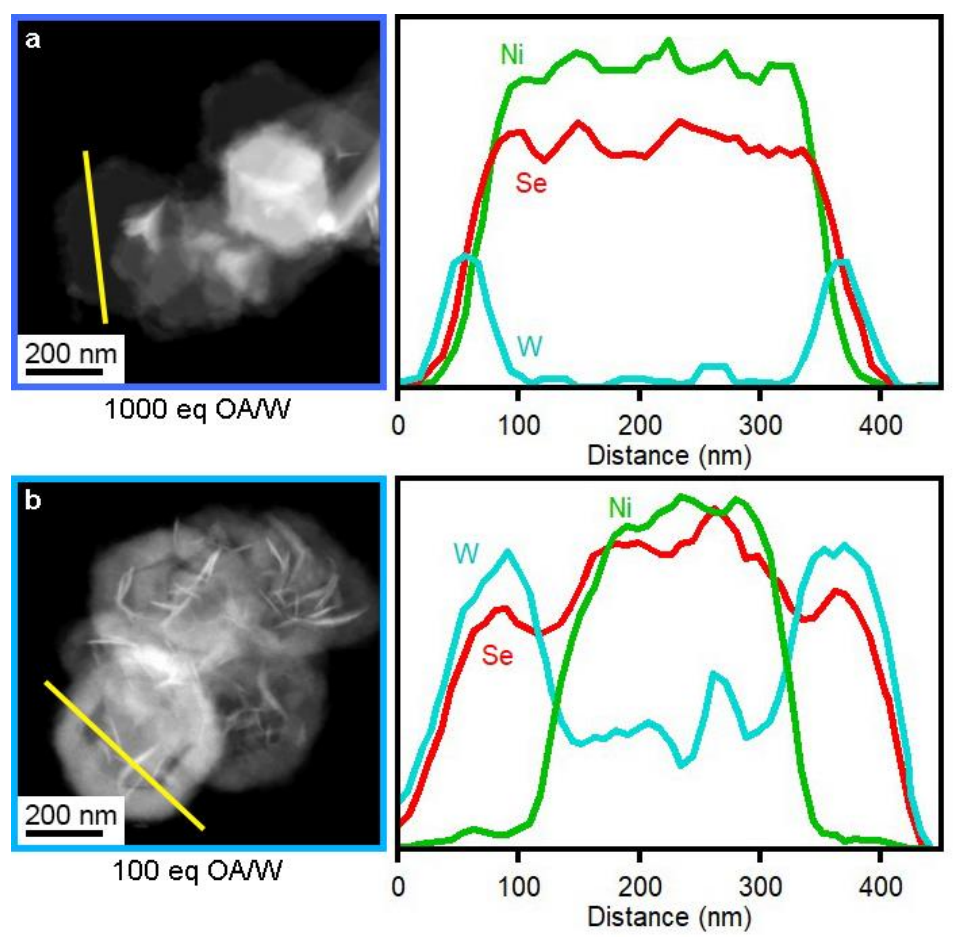

Figure S10. Dark field TEM images and corresponding line-scans of $\mathrm{WSe}_{2}$ grown onto $\mathrm{Ni}_{3} \mathrm{Se}_{4}$ nanoplatelets in the presence of (a) $1000 \mathrm{eq} \mathrm{OA} / \mathrm{W}$ and (b) $100 \mathrm{eq}$ $\mathrm{OA} / \mathrm{W}$. The line-scan of the 100-eq heterostructures reveals a ratio of $\sim 2: 1 \mathrm{~W}$ on the nanocrystal edge:face. The ratio of edge:face $\mathrm{W}$ is clearly much lower than 2:1 in the 1000-eq heterostructures, suggesting that edge growth is preferred. 


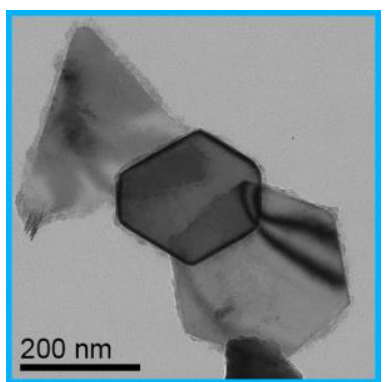

Figure S11. TEM image of aliquot taken at $5 \mathrm{~min}$ of shell-growth of $\mathrm{WSe}_{2}$ in the presence of $100 \mathrm{eq} \mathrm{OA} / \mathrm{W}$. Only deposition of the $\mathrm{WSe}_{2}$ at the edges is observed.

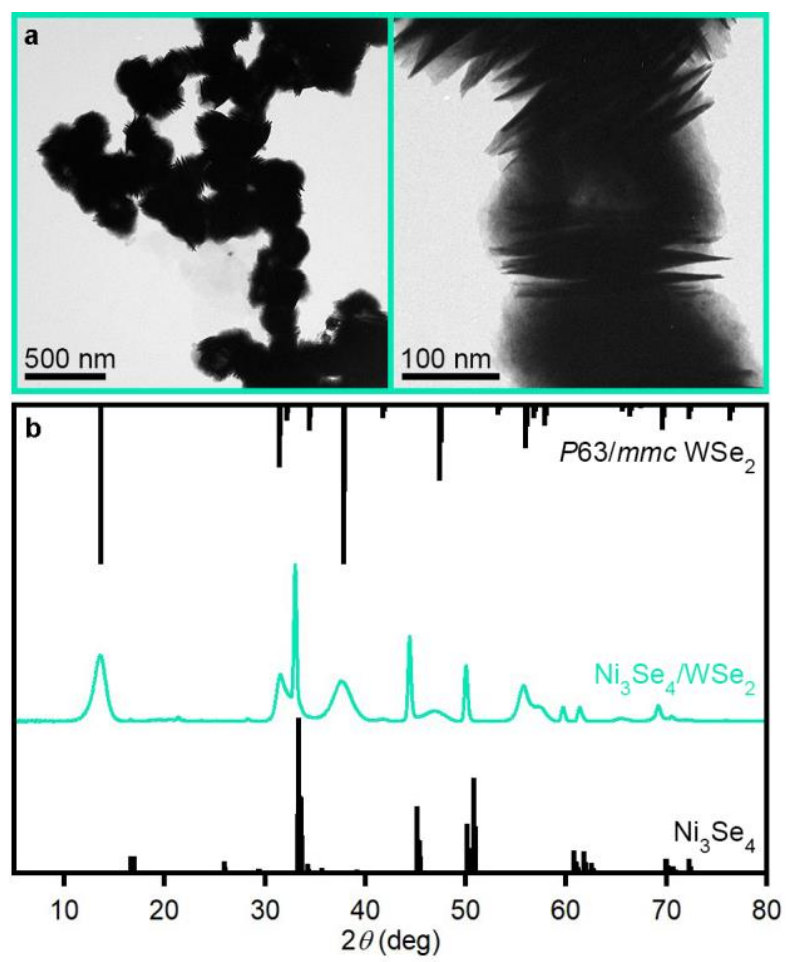

Figure S12. (a) TEM images and (b) powder X-ray diffraction pattern of $\mathrm{Ni}_{3} \mathrm{Se}_{4} / \mathrm{WSe}_{2}$ heterostructures synthesized in the presence of 100 eq phenylacetic acid (PAA). Specifically, $0.15 \mathrm{mmol} \mathrm{Ph}_{2} \mathrm{Se}_{2}$ in $0.75 \mathrm{ml} \mathrm{ODE}$ was rapidly injected into a solution of $0.05 \mathrm{mmol} \mathrm{Ni(acac})_{2}$ and $0.03 \mathrm{mmol} \mathrm{W}(\mathrm{CO})_{6}$ in $0.39 \mathrm{~g}$ PAA and $8.9 \mathrm{~g}$ TOPO at $330{ }^{\circ} \mathrm{C}$. This synthesis yields heterostructures shelled with the thermodynamically favored $2 \mathrm{H}$ phase of $\mathrm{WSe}_{2}$, possibly due to greater mobility of the PAA ligand and/or to lower ligand amounts. ${ }^{1}$ This synthesis could not be performed at 1000 eq PAA/W due to the lower boiling point of PAA. 

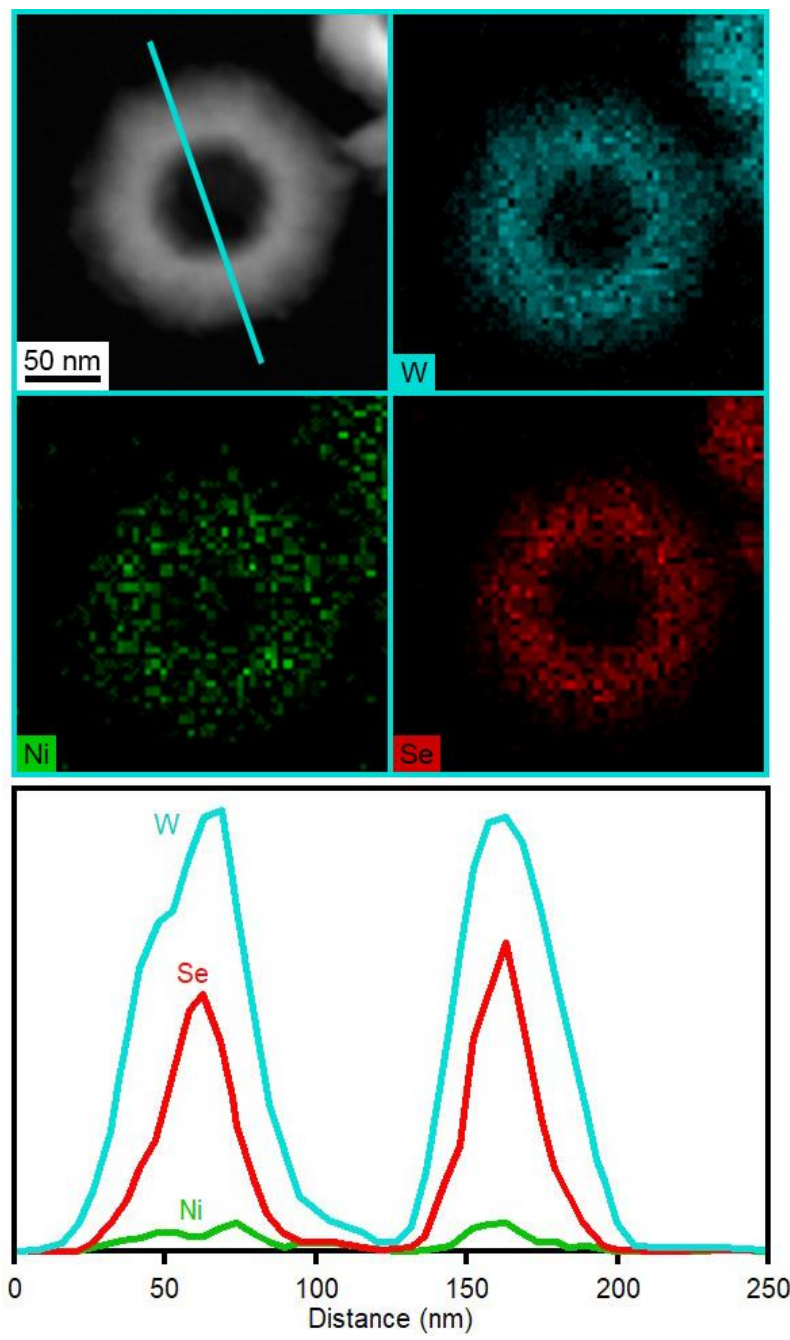

Figure S13. STEM-EDS mapping images and corresponding line-scan of hollow WSe 2 nanocrystals formed by anaerobic treatment of heterostructures with $\mathrm{Et}_{2} \mathrm{~N}_{2} \mathrm{H}_{4}$ and TOP in chloroform for 3 days. Small amounts of Ni remaining in the shell are likely due to co-intercalation with $\mathrm{Et}_{2} \mathrm{~N}_{2} \mathrm{H}_{4}$. 


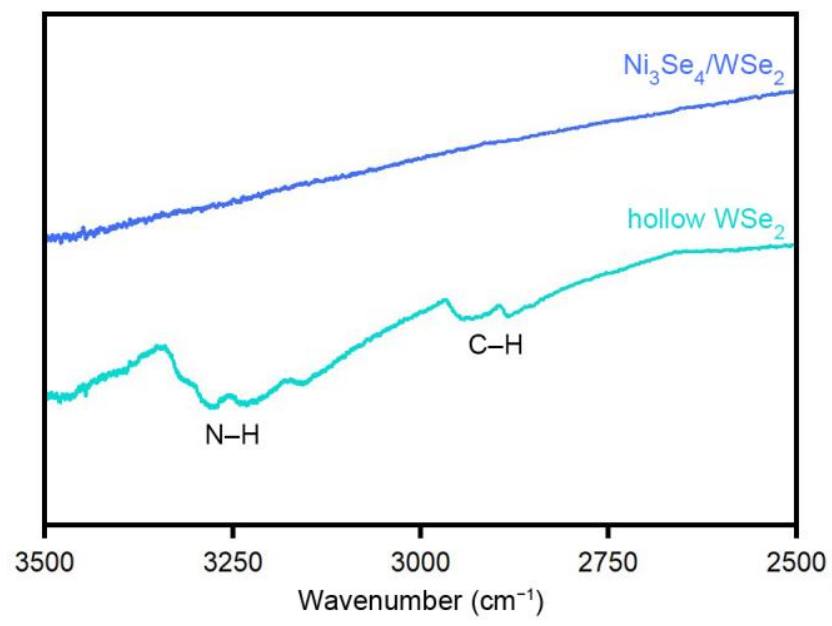

Figure S14. IR absorption of $\mathrm{Ni}_{3} \mathrm{Se}_{4} / \mathrm{WSe}_{2}$ heterostructures (top, blue) after 3 washes post-synthesis, showing no detectable ligands remaining. The heterostructures were soaked anaerobically with $\mathrm{Et}_{2} \mathrm{~N}_{2} \mathrm{H}_{4}$ and TOP in chloroform for 3 days, after which they were washed 5 times with $9 \mathrm{ml} \mathrm{H}_{2} \mathrm{O} / \mathrm{EtOH}$ (1:2). The IR absorption of the resulting hollow nanocrystals (bottom, teal) shows $\mathrm{N}-\mathrm{H}$ and $\mathrm{C}-\mathrm{H}$ stretches, indicative of $\mathrm{Et}_{2} \mathrm{~N}_{2} \mathrm{H}_{4}$ intercalation.

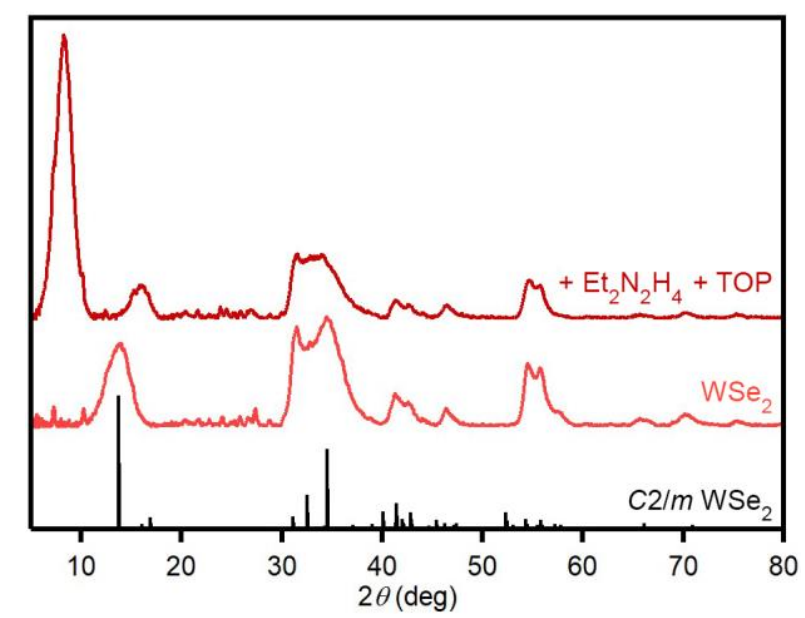

Figure S15. Powder X-ray diffraction patterns of $\mathrm{WSe}_{2}$ nanocrystals before (bottom) and after (top) anaerobic treatment with $\mathrm{Et}_{2} \mathrm{~N}_{2} \mathrm{H}_{4}$ and TOP in chloroform for 3 days. The $\mathrm{WSe}_{2}$ nanocrystals were synthesized following a previously published procedure. ${ }^{1}$ The $\mathrm{WSe}_{2}$ interlayer expansion of 0.41 following intercalation is less than that observed when $\mathrm{Ni}$ is present, further supporting cointercalation of $\mathrm{Ni}$ along with $\mathrm{Et}_{2} \mathrm{~N}_{2} \mathrm{H}_{4}$ in the case of the heterostructures. 


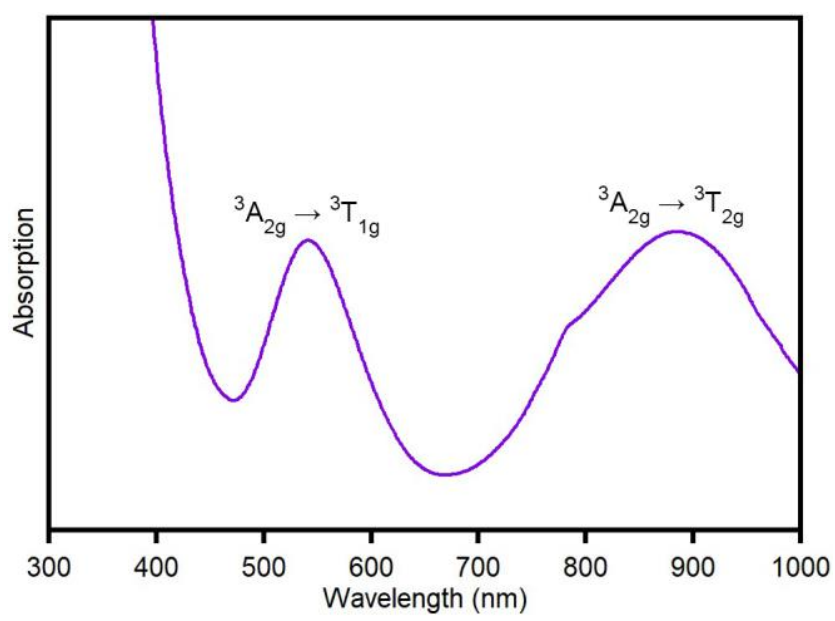

Figure S16. Absorption spectrum of complex isolated from supernatant after $\mathrm{Ni}_{3} \mathrm{Se}_{4} / \mathrm{WSe}_{2}$ heterostructures were anaerobically treated with $\mathrm{Et}_{2} \mathrm{~N}_{2} \mathrm{H}_{4}$ and TOP in chloroform for 3 days. The location of the ${ }^{3} \mathrm{~A}_{2 \mathrm{~g}} \rightarrow{ }^{3} \mathrm{~T}_{2 \mathrm{~g}}(884 \mathrm{~nm})$ and ${ }^{3} \mathrm{~A}_{2 \mathrm{~g}} \rightarrow{ }^{3} \mathrm{~T}_{1 \mathrm{~g}}$ $(541 \mathrm{~nm})$ transitions are indicative of $\left[\mathrm{Ni}\left(\mathrm{Et}_{2} \mathrm{~N}_{2} \mathrm{H}_{4}\right)_{3}\right]^{2+}{ }^{2}$

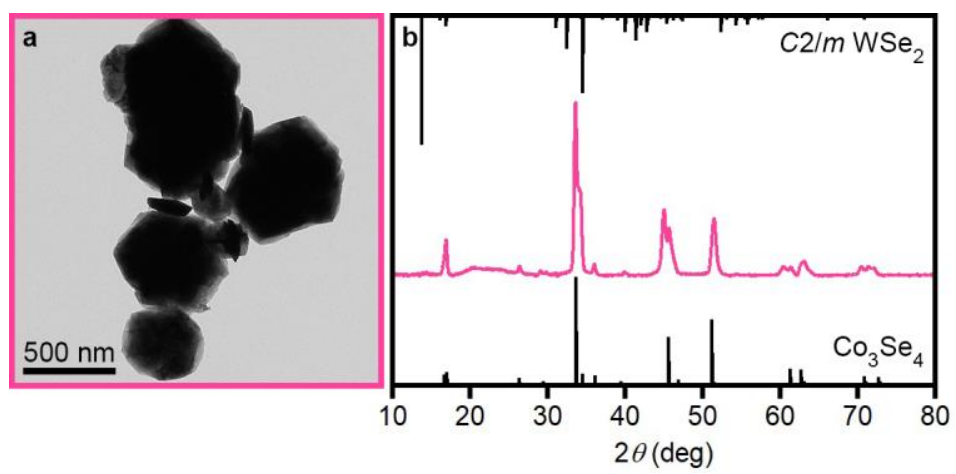

Figure S17. (a) TEM image and (b) powder X-ray diffraction pattern of $\mathrm{Co}_{3} \mathrm{Se}_{4} / \mathrm{WSe}_{2}$ heterostructures synthesized by injection of $0.3 \mathrm{mmol} \mathrm{Ph}_{2} \mathrm{Se}_{2}$ in 1.5 $\mathrm{ml} \mathrm{OA}$ into a solution of $0.1 \mathrm{mmol} \mathrm{Co(acac})_{3}$ and $\left.0.06 \mathrm{mmol} \mathrm{W(CO}\right)_{6}$ in $17 \mathrm{ml} \mathrm{OA}$ and $2 \mathrm{~g}$ TOPO at $330{ }^{\circ} \mathrm{C}$. Nanocrystals were grown for $30 \mathrm{~min}$. 


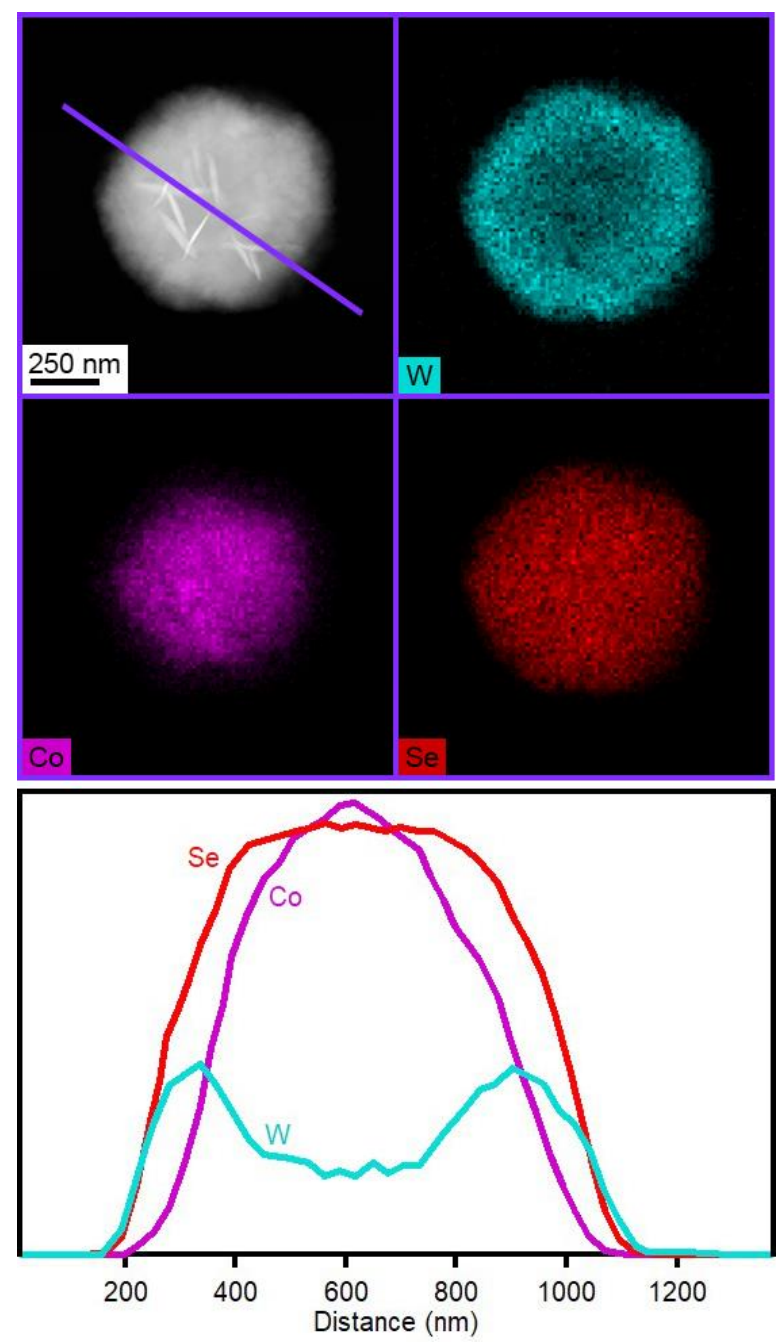

Figure S18. STEM-EDS mapping images and corresponding line-scan of $\mathrm{Co}_{3} \mathrm{Se}_{4} / \mathrm{WSe}_{2}$ heterostructures synthesized by rapid injection of $0.5 \mathrm{mmol} \mathrm{Ph}_{2} \mathrm{Se}_{2}$ in $2.5 \mathrm{ml} \mathrm{OA}$ into a solution of $0.1 \mathrm{mmol} \mathrm{Co(acac})_{3}$ and $0.13 \mathrm{mmol} \mathrm{W}(\mathrm{CO})_{6}$ in 17 $\mathrm{ml} \mathrm{OA}$ and $4 \mathrm{~g}$ TOPO at $330^{\circ} \mathrm{C}$. Nanocrystals were grown for $2 \mathrm{~h}$. 


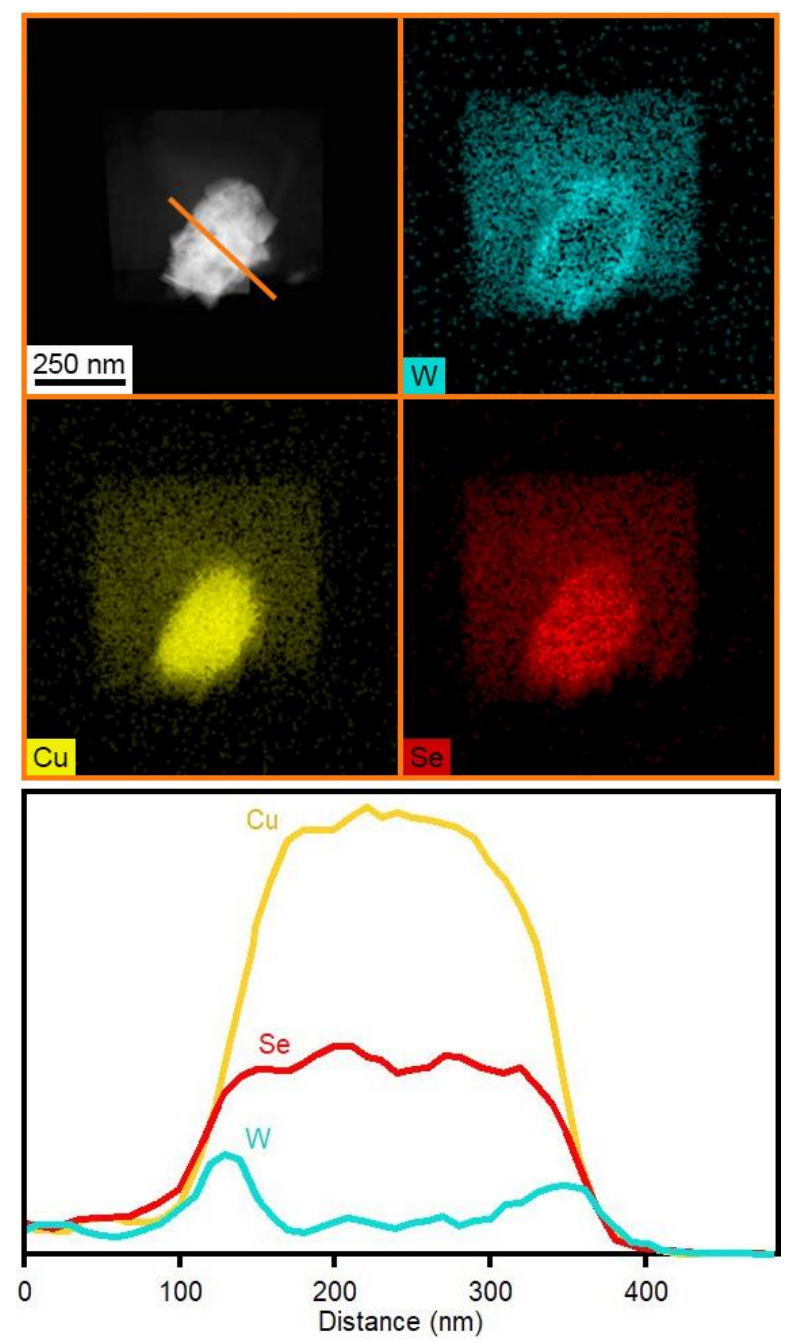

Figure S19. STEM-EDS mapping images and corresponding line-scan of $\mathrm{Cu}_{2-x} \mathrm{Se} / \mathrm{Cu}_{2} \mathrm{WSe}_{4}$ heterostructures synthesized by rapid injection of $0.3 \mathrm{mmol}$ $\mathrm{Ph}_{2} \mathrm{Se}_{2}$ in $1.5 \mathrm{ml} \mathrm{OA}$ into a solution of $0.1 \mathrm{mmol} \mathrm{CuCl}$ and $0.06 \mathrm{mmol} \mathrm{W}(\mathrm{CO})_{6}$ in $17 \mathrm{ml} \mathrm{OA}$ and $2 \mathrm{~g}$ TOPO at $330{ }^{\circ} \mathrm{C}$. Nanocrystals were grown for $60 \mathrm{~min}$. Mapping reveals a $\mathrm{Cu}_{2}-x \mathrm{Se}$ with a shell of $\mathrm{Cu}_{2} \mathrm{WSe}_{4}$ surrounded by a thin sheet of $\mathrm{Cu}_{2} \mathrm{WSe}_{4}$. 


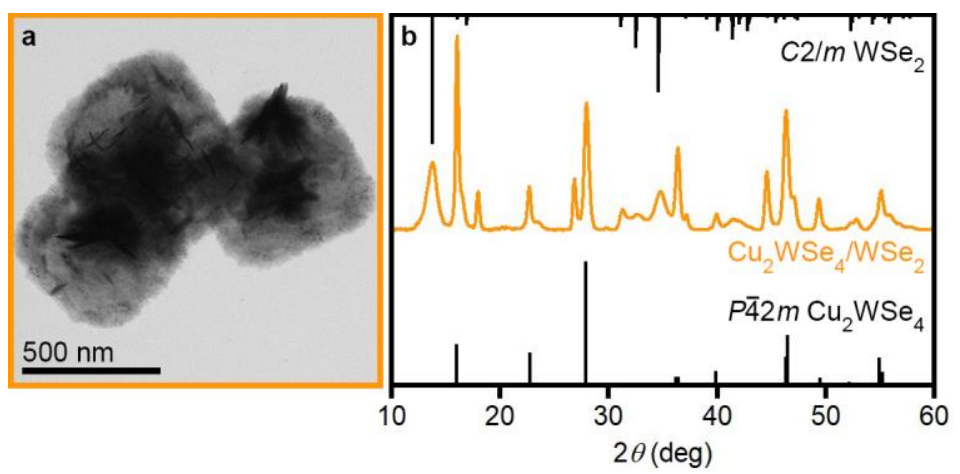

Figure S20. (a) TEM image and (b) powder X-ray diffraction pattern of 60-min aliquot for synthesis of $\mathrm{Cu}_{2} \mathrm{WSe}_{4} / \mathrm{WSe}_{2}$ heterostructures synthesized by dropwise addition of $0.5 \mathrm{mmol} \mathrm{Ph}_{2} \mathrm{Se}_{2}$ in $2.5 \mathrm{ml} \mathrm{OA}$ into a solution of $0.1 \mathrm{mmol} \mathrm{CuCl}$ and $0.23 \mathrm{mmol} \mathrm{W}(\mathrm{CO})_{6}$ in $17 \mathrm{ml} \mathrm{OA}$ and $5 \mathrm{~g}$ TOPO at $330{ }^{\circ} \mathrm{C}$. The powder pattern reveals a small amount of $\mathrm{Cu}_{2-x} \mathrm{Se}$ remaining in the core.

\section{References}

1. Geisenhoff, J. Q.; Tamura, A. K.; Schimpf, A. M., Using Ligands to Control Reactivity, Size and Phase in the Colloidal Synthesis of WSe2 Nanocrystals. Chem. Commun. 2019, 55, 8856.

2. Sun, K. Q.; Marceau, E.; Che, M., Evolution of Nickel Speciation During Preparation of Ni$\mathrm{SiO}_{2}$ Catalysts: Effect of the Number of Chelating Ligands in $\left[\mathrm{Ni}(\mathrm{en})_{x}\left(\mathrm{H}_{2} \mathrm{O}\right)_{6-2 x}\right]^{2+}$ Precursor Complexes. Phys. Chem. Chem. Phys. 2006, 8, 1731. 